\title{
Construction of the Applied Chemistry Major Experimental Teaching Center in the Background of Local University Type Transformation
}

\author{
Jun Wang* Zheng-Hao Fei Jian-Qing Tao \\ School of Chemistry and Environmental Engineering, Yancheng Teachers University, No. 2, Hope Avenue \\ South Road, Jiangsu 224007, China
}

\begin{abstract}
The professional experimental teaching demonstration center is an important practice base for the cultivation of applied talents. The experimental teaching demonstration center of applied chemistry of Yancheng Teachers University was taken as an example to explore the construction of the professional experimental teaching system of local undergraduate university under the background of transformation. Furthermore, the methods to strengthen the students' engineering practice ability training, the students' application innovation ability training, and the experimental teaching quality guarantee mechanism have also been explored and discussed. Through the construction of the experimental teaching demonstration center, the quality of experimental teaching and the quality of applied talents could be improved.
\end{abstract}

Keywords: local university transformation; experimental teaching demonstration center; the applied chemistry major; construction and operation

DOI: $10.7176 / \mathrm{JEP} / 10-15-17$

Publication date:May $31^{\text {st }} 2019$

\section{Introduction}

Under the background of the transformation and development of local undergraduate universities, the quality of personnel training has been continuously improved to meet the needs of regional economic development in the applied chemistry major of Yancheng Teachers University. The applied chemistry major has strong engineering practice characteristics and necessary to equip some professional practice teaching platforms to cooperate with the theoretical teaching system to cultivate the students' engineering practice ability and application innovation ability. Compared with traditional practice teaching, the construction of the new experimental teaching demonstration center should be more targeted, hierarchical and systematic in the context of applied transformation ${ }^{[1-3]}$. The threedimensional practice base for students should be established to achieve the goal of cultivating and strengthen the engineering practice ability and applying innovation ability. The chemistry experiment teaching demonstration center in Yancheng Teachers University was as an example to explore the construction and operation of the experimental teaching demonstration center of local undergraduate universities under the background of transformation in this paper.

\section{The basic situation of the experimental teaching center}

The chemical engineering and technology comprehensive training center of Yancheng Teachers University (hereinafter referred to as the "Center") has the instrument and equipment price of nearly 22 million Yuan, and could accommodate 150,000 hours of experimental training and scientific research tasks per year. The center has become a comprehensive training platform for students in chemical industry and related majors, including experimental experiment, process training, simulation training, chemical design and scientific research innovation after so many years' construction.

\section{The goal of the construction of experimental teaching center}

Mainly relying on the school of chemistry and chemical engineering of Yancheng Teachers University, the goal of the construction of experimental teaching center is to build a comprehensive training center for coastal chemical, environmental and clean production and new materials development technologies, serving emerging application fields such as new energy, new chemicals and new medicines in the coastal development strategy to improve the quality of personnel training and promote the development of students.

\section{The main content and connotation of the construction of experimental teaching center}

\subsection{The construction of teaching staff}

High-level talent construction is regarded as the top priority. The performance appraisal and evaluation mechanism have been built to strengthen the construction of practical teaching, management team and the discipline team construction in a hierarchical and focused manner based on paying equal attention to the importance of talent introduction and training. The specific methods to improve the construction of teaching staff are as follows. Firstly, 
the experimental and practical teaching as the main teacher responsibility system was implemented. The teacher, who is keen on the experimental practice teaching, has experimental and practical teaching experience, and strong sense of responsibility was selected as the course leader in each experimental practice class. Through the course leader to organize the group preparation, lectures, after-school discussion and exchanges, etc., the problems in the experimental teaching were solved to make the experimental teaching the best state. Secondly, the young teacher tutor system was implemented to form the echelon of experimental teaching practice taking the old with new. For the new teachers introduced in the past two years, the instructors would be assigned, and the new teachers would be taught for a period of time. Only after pass through the assessment of trials and experiments, the teacher could carry out the experimental practice teaching. Thirdly, the construction of a double-skilled faculty was strengthened. Through the activities of summer enterprises and institutions, the outstanding teachers would be assigned to the company for internships and part-time jobs to strengthen the engineering practice ability of teachers and the construction of double-skilled faculty. Fourthly, the selection of young and middle-aged teachers to go abroad for further study was intensify to provide them with more opportunities to reach the international frontiers of the discipline. Fifthly, the training of experimental technicians was strengthened to improve the management level of laboratories. The laboratory technicians were invited to visit and exchange studies in other universities to improve the technical level and practical skills of the technicians.

\subsection{The reform of experimental (practical) teaching \\ 4.2.1 The teaching philosophy}

Adhering to the cultivation of talents as the foundation, the construction of applied chemistry brand in Jiangsu Province was taken as the leader to form the teaching ideas of "quality, knowledge and ability". Around the goal of talent training, the following four aspects of work in the process of experimental teaching reform have been completed in the center. Firstly, the team of experimental practice teachers with a high level of professionalism and strong sense of innovation was established. Secondly, some professional and comprehensive training room that is conducive to cultivate the students' innovative consciousness and innovative training were built. Thirdly, the chemical principle experimental devices were improved and updated, and some independent experimental devices was jointly developed with Nanjing Technology University to increase the number comprehensive experimental projects, cultivate the students' self-learning and comprehensive application ability and strengthen the cultivation of the students' design ability to improve the ability of students to work. Fourthly, the schoolenterprise alliance was strengthened to actively carry out the "government, industry, education and research" cooperation. The research activities were jointly carried out with enterprises so that the research results could directly be transformed technology to further shorten the distance between schools and enterprises.

\subsubsection{The thoughts on teaching reform}

The thoughts on teaching reform are as follows. The integration of theoretical teaching and experimental teaching was always emphasized in the process of center construction. The experimental teaching is a necessary link for the cultivation of applied talents, an important link between the integration of theory and practice, and also an indispensable link with social and economic development. Practice teaching and theoretical teaching should be mutually supportive, basic knowledge training and comprehensive design experiments should be rationally set, and intra-campus experiments should be seamlessly connected with off-campus internships. Firstly, the experimental teaching content was optimized to integrate the teaching resources and construct a reasonable system. The number of validation experiments was reduced and the proportions of comprehensive, designing, and innovative experiments were increased as much as possible while ensuring basic experiments. Secondly, the assessment of the experimental teaching process was improved. In the course of experimental teaching, the practical ability of the students' experiments could not be accurately assessed alone by the experimental operation and experimental report. In order to comprehensively evaluate the students' experimental skills, the comprehensive experimental assessment mechanism needs to be established. In addition to the regular test report, the close-book examinations related to the experimental content, the actual operation on the spot, and the on-site answer to the experiment should be added.

\subsubsection{The teaching system and teaching content}

The stereo and open practical teaching system based on the practical teaching within the training program, supplemented by the second classroom such as the students' practical innovation plan and various discipline competitions has been built ${ }^{[4-5]}$. The center adopts advanced teaching methods, systematic design and reform of the scientific and rational experimental teaching management system to guarantee the effective operation of experimental teaching and to realize the goal of cultivating high-quality applied high-level specialized talents. Details as follows: Firstly, the experimental teaching system closely with disciplines and professional development has been constructed. The future development plan of the center would be developed around the development trend of the two provincial key disciplines of chemistry and applied chemistry, the key disciplines of environmental engineering and material chemistry and the applied chemistry brand in Jiangsu Province to improve the talent training quality. Secondly, the teaching content has been updated to strengthen the connection between the theory 
and practice in comprehensive design experiments. The integrated chemical training center consisting of "chemical engineering experiment, chemical cognitive training, chemical unit operation training and chemical design" has been established to train the students' basic skills and practical ability in the center. Thirdly, the latest information technology and scientific research results have been used to continuously innovate experimental projects, which not only strengthened the transformation of scientific research results, but also continuously optimized the experimental projects. For example, in response to the needs of Jiangsu coastal chemical industry and Yancheng local automobile industry development, many experimental projects such as ethyl acetate training and lithium ion battery preparation were opened. Fifthly, the construction of experimental textbooks has been strengthened. Eight experimental textbooks such as "Chemical Principle Experiment" have been published, among which five teaching materials such as "Inorganic Chemistry Experiment" have been rated as the excellent textbooks in Jiangsu Province. The experimental lectures on the two courses of "Ethyl Acetate Training Regulations" and "Chemical Virtual Simulation Experiment" were compiled, which not only reflected the trend of cross-disciplinary and integrated development, but also coincided with the industry development and professional construction.

At present, the experimental teaching system of "experimental resource sharing, experimental data reality, experimental project innovation and experimental training management norms" and three experiment types of "basic experiments, improved experiments, research and innovative experiments" have been established, which are greatly enriched the content of experimental teaching, and improved the effect of experimental teaching.

\subsubsection{The teaching method and teaching means}

Around the training target of applied talents, the advanced teaching methods and teaching methods, the reforms of the scientific and rational experimental teaching management system have been carried out to guarantee the effective operation of experimental teaching, achieve the goal of cultivating high-quality applied high-level professionals and improve the quality of experimental practice teaching. Firstly, the transform from the teachercentered concept of teaching knowledge to the student-centered knowledge has been built. Some new-type teaching methods such as the heuristic teaching method combining "teaching, learning, doing, and using", the network interactive teaching method, a multi-level open practical teaching method and a research-based extracurricular innovative teaching method have been applied. Secondly, a three-in-one experimental project elective mechanism and the combination of decentralized experiment and concentrated experiment, in-class experiment and extra-curricular open experiment have been constructed to cultivate the students' awareness and ability of innovation and entrepreneurship. Thirdly, the implementation of each teaching link was strictly implemented in the process of practical teaching, emphasizing "six implementations" (plan implementation, outline implementation, teacher implementation, site implementation, assessment implementation and fund implementation). Fifthly, the diversified experimental training assessments were actively carried out. For the characteristics of the course, a variety of assessment methods such as "writing test, operation test, project demonstration, and defense" were adopted. Guided by the curriculum standards, the students' participation, representation, length and innovation have been fully considered to improve the students' experimental practice enthusiasm and practical ability in the practice process assessment.

\subsubsection{The teaching effects and teaching achievements}

The revision of the central talent training program was taken as an opportunity to adjust and increase the proportion of experimental class hours. The practice credits in the talent training program was increased to about $20 \%$ of the total credits and the comprehensive design experiments was increased to $70 \%$ of the experimental projects.

In the past four years, the students of the applied chemistry in Yancheng Teachers University actively participate in the competition, and won one gold medal in the National Competition of the 10th College Student Entrepreneurship Competition, one gold medal in 2016 and 2018 "Creating Youth" National Undergraduate Entrepreneurship Competition, the first prize of the 9th, 10th, 11th, and 12th National Undergraduate Chemical Design Competitions and the 1st National Undergraduate Chemical Experiments Competition, the first prize of the 4th Jiangsu University Student Chemistry and Chemical Experiment Competition. In 2016 and 2017, the students of the applied chemistry major won the first prize of the outstanding undergraduate thesis of the provincial colleges and universities and one of the outstanding papers of 2016 was obtained. After many years of the practical exploration in the application of applied chemistry, the students' engineering practice ability, scientific research ability, innovation and entrepreneurial ability have been greatly improved to realize the coordination and balance between the supply side of the talent cultivation and the demand side of the industry. The satisfaction of employers has been greatly improved. At the same time, the professional employment rate of the applied chemistry major was $89.2 \%$, and the graduates have been widely praised by the employers.

\subsection{The intelligent construction of information platform}

The networked experimental teaching and laboratory management information platform has been constructed in the center. All software and hardware resources have been integrated in this platform to facilitate the open management of the laboratory. All experimental courses, experimental outlines, experimental equipment, and scheduled experiments could all be realized through the experimental teaching platform. At the same time, the 
two-way interactive teaching session between teachers and students has been also added to this platform to achieve rapid and effective teaching activities and organizational management. The center relies on the open management platform of Yancheng Teachers University, the graduation (design) paper management platform, the discipline competition management platform, and the university student innovation training management platform to carry out intelligent laboratory opening, graduation design and online course management for students. Through the informatization construction, the practice teaching management is further standardized, and the students are provided with a broader learning platform to promote the improvement of the practical teaching level.

\section{Conclusion}

In the experimental teaching of the applied chemistry major of Yancheng Teachers University, the traditional experimental curriculums were retained to ensure that students could conduct the basic experimental operations and experimental skills training. Some research (innovative) experiments at different levels were open to achieve multi-level and all-round opening in time, space, equipment and teaching content. The combination of "production, learning and research" was emphasized so that the students' experimental teaching could be better combined with the practical applications such as scientific research and engineering, and receives professional training and employment training. Through the practice teaching in the demonstration center, the training of applied chemistry professionals has been further strengthened and the efficient and excellent engineering education models have been formed.

\section{Acknowledgments}

The research is supported by Jiangsu Higher Education Teaching Reform Research Project (2017JSJG209) and the Top-notch Academic Programs Project of Jiangsu Higher Education Institutions (PPZY2015B113).

\section{References}

[1] Cheng Zhang. (2017). Analysis of the Effective Connection between Talent Cultivation and Enterprise Demand in the Perspective of "Five in One". Journal of Henan Judicial Police Vocational College, 15: 122-124.

[2] Xuezhong Liu. (2017). The New Exploration of the System and Mechanism of Collaborative Education for Local Application-oriented Universities. Journal of National Academy of Education Administration, 9: 6772.

[3] Fangyong Tan, Zhen Zhang, Ligang Fang. (2019). Reform of Personnel Training Mode of "Jointly Cultivating Talents via Integrating Production with Teaching" in Vocational Colleges: A Case Study of Computer Network Technology Specialty in Suzhou Vocational University. Joural of zhongzhou university, 30(1): 6568.

[4] Lihua Nie, Lijing Xie, Qiufang Wang, Yuzhou He, Bei Wang. (2019). Exploration and Practice of the StudentCentered Laboratory Center Construction for Preventive Medicine. Chinese Journal of medical equipment, 34: $150-152$.

[5] Hui-Min Jiang, Guo-Hua Chen. (2018). Research on the Cooperative Education Mechanism Between the Universities and Enterprises in Northern Jiangsu Based on University-Industry Cooperation. Education Modernization, 32: 22-24. 